\title{
Erratum zu: Folgen sozialer Hilfen
}

\author{
Bernd Dollinger · Hanna Weinbach
}

Online publiziert: 21. Januar 2022

(C) Der/die Autor(en) 2022

\section{Erratum zu:}

\section{Soz Passagen 2020}

https://doi.org/10.1007/s12592-020-00340-7

Der Artikel Folgen sozialer Hilfen von Bernd Dollinger und Hanna Weinbach wurde ursprünglich Online First ohne „Open Access“ auf der Internetplattform des Verlags publiziert. Nach der Veröffentlichung in Band 12 Heft 1 pp. 179-184 hatten sich der Autor für eine „Open Access“-Veröffentlichung entschieden. Das Urheberrecht des Artikels wurde deshalb in (C) Der/die Autor(en) 2021 geändert. Dieser Artikel ist jetzt unter der Creative Commons Namensnennung 4.0 International Lizenz veröffentlicht, welche die Nutzung, Vervielfältigung, Bearbeitung, Verbreitung und Wiedergabe in jeglichem Medium und Format erlaubt, sofern Sie den/die ursprünglichen Autor(en) und die Quelle ordnungsgemäß nennen, einen Link zur Creative Commons Lizenz beifügen und angeben, ob Änderungen vorgenommen wurden.

Die in diesem Artikel enthaltenen Bilder und sonstiges Drittmaterial unterliegen ebenfalls der genannten Creative Commons Lizenz, sofern sich aus der Abbildungslegende nichts anderes ergibt. Sofern das betreffende Material nicht unter der ge-

Die Online-Version des Originalartikels ist unter https://doi.org/10.1007/s12592-020-00340-7 zu finden.

Prof. Dr. Bernd Dollinger $(\varangle)$

Fakultät II, Department Erziehungswissenschaft · Psychologie , Universität Siegen, Adolf-Reichwein-Straße 2a, 57068 Siegen, Deutschland

E-Mail: bernd.dollinger@uni-siegen.de

Dr. Hanna Weinbach

Sozialpädagogik, Zentrum für Planung und Evaluation Sozialer Dienste (ZPE), Universität Siegen, Hölderlinstr. 3, 57068 Siegen, Deutschland

E-Mail: hanna.weinbach@uni-siegen.de 
nannten Creative Commons Lizenz steht und die betreffende Handlung nicht nach gesetzlichen Vorschriften erlaubt ist, ist für die oben aufgeführten Weiterverwendungen des Materials die Einwilligung des jeweiligen Rechteinhabers einzuholen.

Open Access Dieser Artikel wird unter der Creative Commons Namensnennung 4.0 International Lizenz veröffentlicht, welche die Nutzung, Vervielfältigung, Bearbeitung, Verbreitung und Wiedergabe in jeglichem Medium und Format erlaubt, sofern Sie den/die ursprünglichen Autor(en) und die Quelle ordnungsgemäß nennen, einen Link zur Creative Commons Lizenz beifügen und angeben, ob Änderungen vorgenommen wurden.

Die in diesem Artikel enthaltenen Bilder und sonstiges Drittmaterial unterliegen ebenfalls der genannten Creative Commons Lizenz, sofern sich aus der Abbildungslegende nichts anderes ergibt. Sofern das betreffende Material nicht unter der genannten Creative Commons Lizenz steht und die betreffende Handlung nicht nach gesetzlichen Vorschriften erlaubt ist, ist für die oben aufgeführten Weiterverwendungen des Materials die Einwilligung des jeweiligen Rechteinhabers einzuholen.

Weitere Details zur Lizenz entnehmen Sie bitte der Lizenzinformation auf http://creativecommons.org/ licenses/by/4.0/deed.de. 